\title{
GCU
}

Glasgow Caledonian

University

University for the Common Good

\section{Emotions and scope effects in the monetary valuation of health}

Avilés Blanco, Maria V.; Brey, Raúl ; Araña, Jorge; Pinto Prades, Jose Luis

Published in:

European Journal of Health Economics

DOI:

$10.1007 / \mathrm{s} 10198-017-0885-7$

Publication date:

2018

Document Version

Author accepted manuscript

Link to publication in ResearchOnline

Citation for published version (Harvard):

Avilés Blanco, MV, Brey, R, Araña, J \& Pinto Prades, JL 2018, 'Emotions and scope effects in the monetary valuation of health', European Journal of Health Economics, vol. 19, no. 3, pp. 315-325.

https://doi.org/10.1007/s10198-017-0885-7

\section{General rights}

Copyright and moral rights for the publications made accessible in the public portal are retained by the authors and/or other copyright owners and it is a condition of accessing publications that users recognise and abide by the legal requirements associated with these rights.

Take down policy

If you believe that this document breaches copyright please view our takedown policy at https://edshare.gcu.ac.uk/id/eprint/5179 for details of how to contact us. 


\section{Emotions and Scope Effects in the Monetary Valuation of Health}

Keywords: health technology evaluation; scope sensitivity; emotions; willingness to pay.

Classification Codes: H41; H51; I11; I18; I31;

María V. Avilés Blanco, University of Seville (Spain) maviles1@us.es

Raúl Brey, University Pablo de Olavide, Seville (Spain) rbresan@upo.es

Jorge Araña, University of Las Palmas de Gran Canaria (Spain) jorge.arana@ulpgc.es

José Luis Pinto Prades, University of Navarra (Spain) jlpinto@unav.es and Glasgow

Caledonian University (joseluis.pinto@gcu.ac.uk) 


\begin{abstract}
This study presents evidence about the role of emotions in the monetary evaluation of health technologies, namely, Drug Eluting Stents (DES) in our case. It is shown that subjects who are very afraid of having to undergo an angioplasty are: a) less sensitive to the size of the risk reduction provided by DES and b) willing to pay more. The lack of scope sensitivity questions the normative validity of the responses of highly emotional subjects. We provide evidence of this effect using what we call the Cognitive-Emotional Random Utility Model and the responses of a face-to-face, computer assisted personal interview survey conducted in a representative sample of the Spanish general population $(n=1663)$.
\end{abstract}




\section{Introduction}

The influence of emotions in human behaviour has attracted an increasing interest in economics (Bechara et al., 1997; Diamond and Vartiainen, 2007; Rick and Loewenstein, 2008). It has been shown that emotions shape individual preferences in consumer behaviour (Ariely, 2009; Lee et al., 2009; Hermalin and Isen, 2008; Shiv and Fedorikhin, 1999), investment choices (Chan and Andrade, 2011), economic transactions (Shiv et al., 2005; Lerner et al., 2004) and in policy evaluation (Araña and León, 2009; Bodenhausen et al., 2000; Bernheim and Rangel, 2007).

The role of emotions can be particularly important in health technology evaluation, since changes in health status are likely to trigger patients' emotional reactions. Emotions such as anxiety or embarrassment have been shown to influence patients' preferences for treatments or screening tests (Elit et al., 1996; Sebban et al., 1995; Robbins et al., 2002, Yasunaga et al. 2007; Jonas et al. 2010). Subjects are willing to pay substantial amounts of money to avoid injectable drugs and this is explained by emotions such as anxiety associated with needles (Matthews et al., 2001; Sadri et al., 2005). The emotional load of caregivers influence preferences for Alzheimer treatments (König et al., 2013; König and Wettstein, 2002; Gervès et al., 2013). Parents’ emotions influence their willingness to pay (WTP) for treatments that improve their children's health status (Kuppermann et al., 2000; Liu et al., 2000; Meyerhoff et al., 2001). Araña et al. (2008) found that emotional individuals are less prone to take appropriate decisions in the context of health care evaluation. Lee et al. (1997) found that fear influences patients' WTP for an autologous blood transfusion, concluding that costeffectiveness analysis should include the benefits of avoiding patient's fear for such a measure. In summary, there is evidence emotions influence WTP for a health intervention. However, there is no evidence about the potential relationship between 
emotions and the sensitivity of WTP responses to the magnitude of the benefit provided by a health technology. The existence of this sensitivity is crucial if the results of a WTP can be used as a guide of social policy, that is, health providers are expected to pay more for a new technology as long as it is better than the status quo. If this marginal WTP has to be based on the responses of individuals to a survey, subjects have to be WTP more for the better technology. This paper presents evidence that emotions reduce the sensitivity of WTP values to the size of the benefit provided by a medical technology questioning the use of those responses in social policy.

Evidence that emotions may affect sensitivity to scope was provided for the first time by Hsee and Rottenstreich (2004) in a very different context (music CDs). They showed that when subjects are in a highly emotional state their WTP hardly changes with the amount of the good provided. They argue that high levels of anticipated emotions reduce sensitivity to scope because "feelings depend on the nature of a stimulus but not on its scope" (p.24). Emotions are driven by the presence or the absence of the stimulus and not by the amount of it (scope). The implication of this effect would be that WTP values very influenced by emotions would not be good indicators of the social value of health technologies. Sensitivity to scope is a desirable property of elicited utility functions, and an important requirement by many analysts who use contingent valuation results to inform health policy (Carson and Mitchell, 1993; Hausman, 2012).

Despite the relevance of this research question, there is scarce evidence in the economics literature in general, and in the case of medical technologies in particular, about the implications of emotions in contingent valuation. This paper explores the role of emotions in the monetary valuation of an specific health technology (i.e. DES): will emotions produce WTP values for medical treatments sensitive to the magnitude of the health benefits associated with different interventions? We provide this evidence using 
data from a study where subjects were asked their WTP to reduce the risk of restenosis (i.e. the risk of needing an operation to implant a stent in their arteries). Different types of stents would result in different risk reductions (Baumgart et al., 2007; Chan et al., 2005; Greenhalgh et al., 2010; Kelbaek et al., 2006; Suttorp et al., 2006) making it possible to test the sensitivity of elicited WTP to changes in risk reduction. If the Hsee and Rottenstreich (2004) hypothesis is confirmed, the monetary value of stents will hardly change with the risk reduction associated with the technology for highly emotional subjects.

It is true that willingness to pay is not the main methodology to evaluate medical technologies, however some agencies allow the possibility of using willingness to pay studies (Mathes et al 2013). In the specific case of Spain, while Cost-Effectiveness and Cost-Utility are the techniques most widely used, willingness to pay studies are also allowed if it is understood that they can provide more information about the social value of a health technology (Corbacho and Pinto-Prades, 2013). There are also many regulations that affect the health of populations that are influenced by willingness to pay studies; for example, concepts like the Value of a Statistical Life and non-fatal injuries used to evaluate some investments are based on willingness to pay studies. It is highly possible that surveys used to estimate willingness to pay for risk reductions in those fields are also influenced by emotions.

The main results of our study are: a) subjects who are more afraid of having an angioplasty are WTP more than those who were less afraid; b) subjects who are more afraid of having an angioplasty are less sensitive to the amount of benefit (e.g. risk reductions) provided by new stents than subjects who are less afraid c) the difference in WTP between subjects with high and low fear was mainly concentrated in the smallest 
level of risk reduction, and was significantly reduced for the highest risk reduction level. Therefore, it seems that emotions change the utility function.

The results have direct implications for the analysis of stated preference methods in health economics. In particular, the validity of the monetary values that do not consider the emotional dimension is in question as guides for social policy (e.g. the price that the health system has to pay for a new and better stent). These results provide empirical support in the area of valuation of health technologies of previous findings of lab experiments using students and simple objects like music CDs (Hsee and Rottenstreich, 2004). This is important since it suggests that the role of emotions in the monetary valuation of objects can be a general phenomenon present in very different contexts. Finally, the role of emotions can also be relevant for other preferences elicitation techniques like Time Trade-Off. We believe that our results have interest for a broad audience, not only for those interested in the evaluation of one medical technology like stents.

The rest of the paper is organized as follows. Section 2 presents the details of the fieldwork and the experiment. Section 3 defines the main hypothesis based on the random utility model (RUM) (McFadden, 1974). Section 4 presents the results. Finally, section 5 discusses some implications of the results, the limitations of the analysis and some avenues for further research.

\section{Fieldwork}

\section{Sampling}

The survey was conducted using a Computer Assisted Personal Interview (CAPI) methodology in February-April 2009. The sampling universe was population living in 
Spain older than 19 years old. The sampling procedure was as follows: primary sampling units were 108 municipalities selected from the 17 Spanish regions. Municipalities were selected to be representative of seven categories of habitat size: less than 2,$000 ; 2,001-10,000 ; 10,001-50,000 ; 50,001-100,000 ; 100,001-400,000 ; 400,001-$ $1,000,000$, more than $1,000,000$ residents. Secondary sampling units were houses selected with random routes. In-house selection was according to proportions based on gender and age. The survey sample size was 1,663.

\section{The Intervention: The Angioplasty Programme}

The questionnaire was divided into three main sections. In the first section participants were informed that the objective of the study was to estimate the value of a health technology. The interviewer provided information about causes, symptoms and consequences (angina, heart attack) of coronary stenosis. The description was facilitated with cards and pictures (Visual Aid). Once the problem was described the survey proceeded to explain the medical treatment. It was explained what an angioplasty involves and that in most cases a stent is implanted in the occluded artery. Two types of stents were described, a Bare-Metal Stent (BMS) and a Drug-Eluting Stent (DES). It was explained that BMS were not coated with drugs while DES were. We explained that the objective of coating the stent with drugs was to reduce the need of having a new angioplasty but that the risk was never zero.

\section{The Evaluation Task}

This section presented the subjects the WTP question. It started with some questions to check that respondents understood the benefits of DES over BMS. They were shown 4 different probabilities of needing a second angioplasty with BMS (e.g. 39\%, 34\%, 29\% 
and $24 \%$ ) and they were asked to compare those probabilities with the probability of needing a second angioplasty with a DES. The probability for a DES was kept at $7 \%$. They were asked in which of the four cases a DES produced a higher benefit. If they did not provide the right answer the system invited them to rectify although their original response was recorded.

The next task was to choose between DES and BMS based only on the health benefit (reduction in the risk of restenosis). They were asked:

Now imagine you feel symptoms like chest pain or shortness of breath and you are diagnosed with the kind of heart problem described in the previous section: a coronary artery is blocked and you require surgery. The doctor then asks you whether you would prefer to have implanted a drug eluting stent or a bare metal stent.

Individuals who preferred the BMS (in spite of having higher risks) were asked the reason for choosing a treatment with higher risks. They were not asked any WTP question and they were taken to the sociodemographics section.

Those who preferred a DES were asked to assume that the national health service only funded the BMS and that they had to pay for the DES. They had to choose between a stent with higher risk and no cost (BMS) or with lower risk and higher cost (DES). They were reminded that the money they were WTP would not be available for other purposes. They were also reminded that they could also pay with a loan, gradually over time. Then they were asked the following WTP question ${ }^{1}$ :

Assume that the doctor tells you that if you choose a Bare Metal Stent, without extra costs for you, you have a 39\% probability of requiring further surgery. That is, out of 100 patients that have the Bare Metal Stent, 39 patients will have to undergo surgery 
within one or two years because the artery will be blocked again and they will suffer the symptoms. The doctor also says that if you choose a Drug Eluting Stent, you have a 7\% probability of requiring further surgery. That is, out of 100 patients that have the Drug Eluting Stent, 7 patients will have to undergo surgery within one or two years. However, there are some costs involved for you. Therefore, you have two options:

\section{Option A: a Bare Metal Stent implanted}

- You have a $39 \%$ risk of repeated revascularization (39 out 100 patients needs further surgery within one or two years)

- No costs involved
Option B: a Drug Eluting Stent implanted

- You have a $7 \%$ risk of repeated revascularization (7 out 100 patients needs further surgery within one or two years)

- You have to pay for it

Would you choose the Drug Eluting Stent if the cost is Y€ or would you rather prefer not to pay and have the Bare Metal Stent instead?

A second question followed, with a higher or lower bid depending on the previous response. The second bid was higher than the first if the respondent had accepted the bid (bid_up) and it was lower if s/he has rejected it (bid_down). The values of the first bid are selected randomly from a set of bids. The bids were tested in a pilot survey $(n=100)$ and they were chosen so that the range was wide enough to obtain the true WTP curve. Bids are shown in Table 1.

The evaluation task was repeated three more times with different health benefits. That is, each subject was asked 8 WTP dichotomous choice questions corresponding to two WTP questions for each of the four risk levels. There were two different versions of the questionnaire according to the amounts of benefits presented to participants. In one version (the "descending" version), subjects started with a $32 \%$ absolute risk reduction

\footnotetext{
${ }^{1}$ We present the question for a $39 \%$ risk of the BMS. The question was repeated for three other risk
} 
(that is, from $39 \%$ to $7 \%$ ) and then they moved to $27 \%, 22 \%$ and $17 \%$. In the second version, (the "ascending" version) subjects started with $2 \%$ and they moved to $7 \%, 12 \%$ and $17 \%$. These health benefits were selected to reflect the variability of results observed in the literature ${ }^{2}$. Patients with risk factors such as complicated lesions or diabetes show an average absolute risk reduction in the probability of restenosis of more than 30 points if they are implanted a DES instead of a BMS, and for those with uncomplicated lesions, the difference between DES and BMS can be as small as 2 percentual points (Moses et al., 2003; Greenberg et al. 2004). This design makes it possible to test the consistency of the results since the same risk reduction (i.e. 17\%) is presented in two different contexts (ascending and descending). At the end of this section the subject was asked: "does the idea of being operated on cause you fear and/or anxiety?". Individuals responded using a Likert scale from 0 (no fear) to 10 (max fear). This was the question used to measure the emotional impact of an angioplasty. Finally, information was collected on sociodemographic characteristics.

\section{Theoretical Model}

\section{Cognitive Random Utility Model}

In order to be able to estimate patients' preferences for the health intervention from the responses to the contingent valuation study, a utility-based choice model was specified. We adopt the representation of the RUM based on McFadden (1974).

Let us define $x=\left(x_{1}, \ldots, x_{g}\right)$ as a composite private good, with $x \geq 0$, and $p=\left(p_{1}, \ldots, p_{g}\right)$ a vector of associated prices $(p>0)$. Let us also consider that the individual has

\footnotetext{
levels.

${ }^{2}$ The degree of risk reduction depends on several characteristics of the patient (e.g. diabetic or not) or of the lesion (e.g. diameter of the artery in the occluded part).
} 
exogenous income, $m \geq 0$, socio-demographic characteristics represented by vector $s$, a set of emotional states $e=\left(e_{1}, \ldots, e_{k}\right)$, and faces a certain risk of restenosis $q$. For a wellbehaved preference map (i.e. represented by a strictly increasing, continuous, and strictly quasi-concave utility function), utility maximization leads to the following indirect utility function:

$v(p, m, s, e, q)=[\max (u(p, m, s, e, q)): p x-m \leq 0]$

where $v$ is the maximum utility that can be achieved given the individual's budget constraint, socioeconomic status, emotions and the level of health risk she faces.

Let us consider that $q_{A}$ is the risk associated with a BMS (option A in the choice task). If the patient chooses the DES (option B in the choice task), risk will be $\mathrm{q}_{\mathrm{B}}$, where $q_{B}<$ $q_{A}$. Therefore, the patient valuation of a DES can be measured as the equivalent variation or WTP for such intervention $\left(\mathrm{WTP}_{i t}\right)$. Thus, $\mathrm{WTP}_{\mathrm{it}}$ can be defined as the maximum amount of money that individual $i$ would be willing to pay for the proposed intervention at moment $t$, i.e. the monetary equivalent loss that would leave her indifferent between both situations. That is,

$v\left(p, m, s, e, q_{A}\right)=v\left(p, m-W T P_{i t}, s, e, q_{B}\right)$

This formulation is deterministic, since it assumes that the individual knows her utility function and can determine her WTP as a function of her socio-economic characteristics and the level of risk reduction level (Hanemann, 1984). This restriction can be relaxed by assuming that the latent variable $\mathrm{WTP}_{\text {it }}$ is a function of a random unobservable component in addition to the deterministic component of equation (2) (Cameron, 1988). Thus, we can write the WTP of individual $i$ at moment $t$ for the health intervention as, 
$W T P_{i t}=X_{i t}^{\prime} \gamma+e_{i} \alpha+H R R_{i t} \beta+\varepsilon_{i t}$

where $\varepsilon_{i t}$ is a random error term, which is assumed normally distributed with zero mean and $\sigma$ standard error, $\mathrm{X}_{\mathrm{it}}^{\prime} \gamma$ is the linear predictor associated with a regression parameter vector $\gamma$ and a covariate vector $\mathrm{X}_{\mathrm{it}}$ including $(p, m, s), e_{i}$ the emotional state corresponding to individual $i$, and $\mathrm{HRR}_{\mathrm{it}}$ denotes the health risk reduction, that is, $q_{A^{-}}$ $q_{B}$

\section{Cognitive-Emotional Random Utility Model}

A more general specification of the RUM needs to be specified in order to test the role of emotions in the monetary value of stents. In order to do so, we need to extend the standard algebraical representation of the RUM in the context of emotional choices. Based on the existing evidence on the impact of emotions on individual decisionmaking problems (Hsee and Rottenstreich, 2004) and previous efforts aimed at modelling the role of emotions in RUM environments (Araña and León, 2008; León et al., 2014), we propose below an extension.

\section{Emotional Shift Effect on Patient's Valuation}

The emotional variable $\left(\mathrm{e}_{\mathrm{i}}\right)$ is operationalized as a dichotomous variable $\left(\mathrm{HE}_{\mathrm{i}}\right.$, high emotions) taking value 1 if the anticipated emotional level is high, and 0 otherwise. Thus, the anticipated emotional level of the intervention directly affects the WTP for such intervention, that is, the higher the fear for the intervention the higher the WTP for reducing the risks (assuming $\alpha>0$ ). We can call this effect an "emotional shift effect" 
in the utility function, and can be included as an extra term in the deterministic part of the WTP weighted by a parameter $\alpha$.That is,

$$
W T P_{i t}=X_{i t}^{\prime} \gamma+H E_{i} \alpha+H R R_{i t} \beta+\varepsilon_{i t}
$$

\section{Scope Sensitivity Effect on Patient's Valuation}

Hsee and Rottenstreich (2004) claim that individuals experiencing high levels of anticipated emotion will not only value the outcome differently, but also emotions will affect how they value changes in the quality of the good under valuation. In other words, the valuation of any improvement in the intervention (e.g. health risk reduction) will also be completely different among subjects' experiencing high and low level of emotions. More emotional subjects will be less sensitive to the size of the benefit. This hypothesis can be called the "emotional scope sensitivity effect" and can be included in

equation (3b) by allowing the parameter vector for subjects experiencing low level of emotions $\beta_{L E}$ to be significantly different from that one of highly emotional patients $\beta_{H E}=\beta_{L E}+\beta^{*}$.

More specifically we expect $\beta^{*}<0$. That is, we expect people who are highly emotional to be less sensitive to the magnitude of the health gain.

Therefore, an alternative expression of equation (3a) that would make it possible to test both hypotheses (shift and emotional scope sensitivity effects) would be,

$$
W T P_{i t}=X_{i t}^{\prime} \gamma+H E_{i} \alpha+H R R_{i t} \beta_{L E}+H R R_{i t} \times H E_{i} \beta^{*}+\varepsilon_{i t}
$$

Shift effects would be estimated using the parameter $\alpha$ and scope sensitivity using $\beta^{*}$. The predictions are that $\alpha>0$ and $\beta^{*}<0$. 


\section{The Econometric Model}

Since each individual provided eight responses (two WTP questions for each health benefit, and four different health benefits), they could be correlated. The random effects probit model allows these responses to be freely correlated by assuming that the error term of the latent variable WTP $\left(\varepsilon_{\mathrm{it}}\right)$ is the sum of an unobservable characteristic specific to individual $\mathrm{i}\left(w_{\mathrm{i}}\right)$ and a random error term $\left(v_{\mathrm{it}}\right)$ that varies across individuals and responses (Haab, 1997), where $t$ indexes the number of responses per individual. Both $w_{i}$ and $v_{i t}$ follow a normal distribution with a mean of zero and a standard deviation of $\sigma_{w}$ and $\sigma_{v}$, respectively.

The random disturbance $w_{\mathrm{i}}$ is assumed to be uncorrelated with the other regressors and since it only varies with the individual and remains constant over the individual's responses, it introduces correlation between responses of the same individual according to the expression:

$$
\operatorname{Corr}\left(u_{i t}, u_{i s,} t \neq s\right)=\frac{\sigma_{w}^{2}}{\sigma_{w}^{2}+\sigma_{v}^{2}}
$$

where $t$ and $s$ stand for two different responses of individual $i$.

The probability of a "yes" response, conditional on $w_{\mathrm{i}}$, is:

$$
\begin{aligned}
& \operatorname{Pr}(\text { yes })=\operatorname{Pr}\left(W T P_{i t} \geq b_{i d}\right) \\
& =\operatorname{Pr}\left(X_{i t}^{\prime} \gamma+H E_{i} \alpha+H R R_{i t} \beta_{L E}+H R R_{i t} \times H E_{i} \beta^{*}+w_{i}+v_{i t} \geq b i d_{i t}\right) \\
& =\operatorname{Pr}\left(\frac{X_{i t}^{\prime} \gamma+H E_{i} \alpha+H R R_{i t} \beta_{L E}+H R R_{i t} \times H E_{i} \beta^{*}+w_{i}-b i d_{i t}}{\sigma_{v}} \geq-\frac{v_{i t}}{\sigma_{v}}\right)
\end{aligned}
$$


$=\Phi\left(\frac{X_{i t}^{\prime} \gamma+H E_{i} \alpha+H R R_{i t} \beta_{L E}+H R R_{i t} \times H E_{i} \beta^{*}+w_{i}-b i d_{i t}}{\sigma_{v}}\right)=\Phi_{i t}$

where $\Phi$ is the standard normal cumulative density function. The unconditional sample log-likelihood function is obtained by considering all the responses and removing the conditioning on $w_{\mathrm{i}}$ :

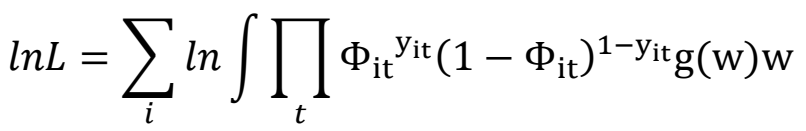

where $\mathrm{y}_{\mathrm{it}}$ is an indicator variable that takes a value of 1 if the $t$ response of the individual $i$ is yes, 0 otherwise; and $\mathrm{g}($.$) is the normal density function of the w_{\mathrm{i}}$.

From these parameters, the mean WTP is computed by using the average of the explanatory variables. In order to make fair comparisons between WTP estimates, these averages have been computed considering the whole sample.

\section{Results}

Sample population is representative of the Spanish population; socioeconomic characteristics of sample and Spanish populations are shown in Table 2. Final sample size was 1,479 distributed in the ascending version $(n=716)$ and in the descending version $(n=763)$ of the questionnaire. There were 149 individuals that preferred the BMS over the DES. The most common cause to reject a DES was fear of the drug that it contains. Observations of 35 individuals that did not provide information on age, employment status or answered "N/A" to a bid were excluded from the analysis.

In order to study the effect of emotions, individuals were classified as having high emotions (i.e. $\mathrm{HE}=1$ ) when their declared level of anxiety and fear was above the median in the Likert scale (i.e. 8, 9 and 10) $(n=729)$, and as LE when the score was 7 or less $(n=750)$. In this way the two subsamples were of similar size ( $n=729$ for HE and 
$\mathrm{n}=750$ for $\mathrm{LE}$ ). The use of the median guarantees enough statistical power to test the proposed hypotheses by using an even distribution of respondents in the high and low emotions group (King and Zeng, 2001).

To control for differences in the composition of the sub-samples, a number of covariates were included in the WTP function: age (number of years), gender (male/female), education (years of study) and employment status (employed/unemployed). The distribution of the covariates age, education and labour status in the four groups is rather similar (see Table 3) but this is not the case for gender. HE groups show a higher presence of female respondents (58 percent), than LE groups (41-44 percent).

Parameter estimates and mean WTP estimates for four different models applied to the ascending and descending groups are shown in Tables 4 and 5, respectively. Model 1 is the base model, where the HE and LE groups are pooled together with no distinction and including the HRR as a continuous variable. Model 2 includes the emotional shift and scope sensitivity effects (variables HE and HRRxHE, respectively). Model 3 includes the HRR by means of the dummy variables $H R R_{R R}$, where RR stands for the risk reduction $\left(\mathrm{HRR}_{7}, \mathrm{HRR}_{12}, \mathrm{HRR}_{17}\right.$ in the ascending group, and $\mathrm{HRR}_{27}, \mathrm{HRR}_{22}$ and $\mathrm{HRR}_{17}$ in the descending group) rather than one continuous variable as done in Model 1, which allows more flexibility in the WTP estimates for each health benefit. Finally, Model 4 uses dummy variables for each level of risk reduction similarly to Model 3, but making a distinction between the $\mathrm{HE}$ and the LE groups ( $\mathrm{LE}_{\mathrm{RR}}$ and $\mathrm{HE}_{\mathrm{RR}}$ dummy variables).

As can be seen in Tables 4 and 5, the portion of the model variance accounted for by individual variation is significant at the $1 \%$ level, indicating that the responses from the first to the eighth question are correlated. This supports the use of a REM econometric specification to analyse the data. 


\section{Emotional Shift Effect on Patients' Preferences}

Results obtained show the existence of an emotional shift. The coefficients associated to the HE variable in model 2 are positive and highly significant, leading to higher WTP estimates for the HE groups in the ascending and descending versions (Tables 4 and 5). This result is not surprising at all since it could be expected that those subjects who are more afraid of the intervention are also WTP more. However, the result is relevant for our research since it shows that the question we used to measure feelings is actually discriminating between subjects according to this characteristic, namely, level of fear.

Similar conclusions are obtained from Models 3 and 4. In these models, the effect of the magnitude of the health benefit on WTP is not constrained to be linear, since dummy variables are used for each level. A likelihood ratio test between Models 3 and 4 finds that there are significant differences on WTP between the HE group and the LE groups for the different levels of health benefit jointly considered (the test statistics are 32.19 and 21.72 in the ascending and descending versions respectively, whereas the $1 \%$ critical value for the chi-squared distribution with 4 degrees of freedom is 13.28).

Moreover, from Model 4, several likelihood ratio tests were carried out to test, for each level of risk reduction and sequence, the equality of coefficients between the $H_{R R}$ and the $\mathrm{LE}_{\mathrm{RR}}$ dummy variables. In all these tests, the null hypothesis of equality is rejected at the $1 \%$ significance level $(1 \%$ critical value for the chi-squared distribution with 1 degree of freedom is 6.63). This point, together with the fact the coefficient estimates of the $\mathrm{HE}_{\mathrm{RR}}$ dummy variables are always higher than their LE counterpart, confirms the presence of an emotional shift in the responses. 
The results show that WTP estimates increase with the amount of risk reduction (e.g. health benefit). The associated parameter to HRR is significant and positive in Models 1 and 2. Similar conclusions are obtained when using dummy variables (Models 3 and 4).

However, sensitivity to scope is sensibly higher for the LE group. The presence of scope effect is tested with the parameter $\left(\beta^{*}\right)$ associated to the interaction HExHRR. For both the ascending and the descending sequences, $\beta^{*}$ are significant at the $5 \%$ level and negative, indicating that the slope of the HE group is lower than the slope of the LE group. This effect is more evident for the ascending sequence since in this case the coefficient of the interaction HExHRR is more strongly negative and more significant (Tables 4 and 5).

Similar conclusions are drawn looking at the WTP estimates obtained with Model 4 (Tables 4 and 5). In the "ascending" version, the WTP estimates for the HE group go from 7,615.86€ to $10,526.95 €$, whereas in the LE group go from 2,597.67€ to 7,953.33€, almost doubling the HE increase. In the descending version, the WTP estimates go from $13,108.86 €$ to $12,096.22 €$ for the HE group and from $9,365.39 €$ to 7,178.24€ for the LE group, being again this difference higher for the LE group (more than doubling in this case).

Finally, the existence of differences for the $17 \%$ risk reduction in the "ascending" and descending versions was tested. This was done by putting together both versions for each level of fear (HE and LE groups). This way all the dummy variables for each risk reduction in the $\mathrm{HE}$ group $\left(\mathrm{HE}_{\mathrm{RR}}, \mathrm{RR}=2,7,12,17,22,27,32\right)$ were estimated simultaneously, making a distinction between $\mathrm{HE}_{17}$ from the ascending version $\left(\mathrm{HE}_{17 \mathrm{Asc}}\right)$ and from the descending version $\left(\mathrm{HE}_{17 \mathrm{Desc}}\right)$, same for the LE group. Next, 
these two models were re-estimated constraining these two dummies to be equal $\left(\mathrm{HE}_{17 \mathrm{Asc}}=\mathrm{HE}_{17 \mathrm{Desc}}\right.$ in the $\mathrm{HE}$ model, and $\mathrm{LE}_{17 \mathrm{Asc}}=\mathrm{LE}_{17 \mathrm{Desc}}$ in the LE model $)$. Two likelihood ratios test were computed between the constrained and unconstrained models, concluding that estimates for a $17 \%$ risk reduction in the ascending and descending versions for each level of fear are not statistically different at the $1 \%$ significance level (the test statistics are 1.682 and 0.842 while the $1 \%$ critical value for the chi-squared distribution with 1 degrees of freedom is 6.63).

\section{Discussion and Concluding Remarks}

The paper shows that emotions can influence the monetary value of health technologies (in this case DES) ${ }^{3}$. Choosing between health technologies is a highly emotional issue and it is not surprising that the evaluation of such technologies is influenced by emotions. The first lesson of this paper is that researchers should try to measure the impact of emotions in the evaluation of such health technologies. This is especially important given that highly emotional subjects not only are WTP more for a reduction in the risk of restenosis (this is perfectly reasonable) but they are not very sensitive to the magnitude of the risk reduction. This seems to confirm Hsee and Rottenstreich (2004) hypothesis that responses to WTP questions mainly reflect the 'nature' of the good (e.g. reduction in the risk of restenosis) and not so much the magnitude of the effect (size of the risk reduction) when emotions are high.

This result has implications for the use of WTP as guidance for public health policy. Assume, for example, that we want to estimate how much a National Health System has to pay for new stents. The main reason that the health system is WTP a higher price for 
new stents is that they produce better outcomes, namely, lower number of restenosis. If we want to use contingent valuation to estimate social WTP, subjects have to be sensitive to the magnitude of the benefit. However, we have seen that, when emotions are high WTP estimates hardly change with the amount of the benefit.

This result questions the normative status of highly emotional responses for social policy. Can we use WTP estimates that do not make any distinction between a $2 \%$ and a $7 \%$ risk reduction? Can we use WTP estimates that reflect a WTP for a $32 \%$ risk reduction that is only $8 \%$ higher than the WTP for a $17 \%$ risk reduction? We think that the response should be negative, that is, emotions should be considered a bias to be corrected. This also opens the issue of the role of emotions in methods like the Time Trade-Off or Standard Gamble. It is not uncommon that subjects provide the same utility for health states that have different severity level. For example, in the case of very bad health states (the so-called worse than death health states) it is quite common for subject to provide the lowest possible utility (e.g. -39 in the former Euroqol protocol). Dolan and Kahneman (2008) suggest that those evaluations are highly influenced by the fear generated by the description of the health problem, so it is possible that the finding that subjects collapse the utility of bad health states (that are actually different) to the lowest possible utility is because all those health states generate the same negative emotions.

We share the Slovic approach (Slovic, 2007) in order to deal with feelings and emotions. Slovic (2007) suggests that people are insensitive to the number of victims in the case of mass murder or genocides because the emotional impact is the same for very different absolute number of victims. In that case, the amount of resources devoted to

\footnotetext{
${ }^{3}$ Similar conclusions in relation to our hypothesis were drawn when using only the response to the first dichotomous choice question for each of the four risk reduction levels. These results are available from the authors upon request.
} 
prevent mass murder cannot be driven by the emotional reaction to the number of victims since it is highly insensitive to scope. In the same way, the price of a stent has to reflect the magnitude of the risk reduction. For this reason, researchers should try to incorporate questions to pick up the effect of emotions in WTP studies of health treatments. They can be used as a debiasing tool or simply as a personality trait that helps to improve our understanding of the responses. If we observe that subjects are not sensitive to scope because they are in a highly emotional state those responses should not be taken into consideration in the case of a public authority that wants to use the results of those studies in order to reimburse the firm that has developed the better stent. We understand that this is a very personal approach about the role of emotion. However, whatever our normative approach to the role of emotions this seems to be a research area that deserves more attention when measuring health benefits. 


\section{References}

Araña, J. E., and León, C. J., 2008. Do emotions matter? Coherent preferences under anchoring and emotional effects. Ecological economics, 66(4), 700-711.

Araña, J.E. and León, C.J., 2009. Understanding the use of non-compensatory decision rules in discrete choice experiments: The role of emotions. Ecological Economics, 68 (8-9), 2316-2326.

Araña, J.E., León, C.J. and Hanemann, W.M., 2008. Emotions and decision rules in discrete choice experiments for valuing health care programmes for the elderly. Journal of Health Economics, 36 (4), 475-497.

Ariely, D., 2009. Predictably Irrational. Harper Collins. New York.

Baumgart, D., Klauss, V., Baer, F., Hartmann, F., Drexler, H., Motz, W., Klues, H., Hofmann, S., Völker, W., Pfannebecker, T., Stoll, H.P., Nickenig, G. and SCORPIUS Study Investigators., 2007. One-year results of the SCORPIUS study: a German multicenter investigation on the effectiveness of sirolimus-eluting stents in diabetic patients. Journal of the American College of Cardiology, 23, 50 (17), 1627-34.

Bechara, A., Damasio, H., Tranel, D. and Damasio, A.R., 1997. Deciding advantageously before knowing the advantageous strategy. Science 275, 1293-1295.

Bernheim, B.D. and Rangel, A., 2007. Behavioural public economies: welfare and policy analysis with non-standard decision-makers. In: Diamond, P. and Vartiainen, H., eds. 2007. Behavioral Economics and Its Applications. Princeton University Press.

Bodenhausen, G.V., Gabriel, S. and Lineberger, M., 2000. Sadness and susceptibility to judgemental bias: the case of anchoring. Psychological Science, 11 (4), 320-323.

Carson, R.T. and Mitchell, R.C., 1993. The issue of scope in contingent valuation studies. American Journal of Agricultural Economics, 75(5), 1263-1267.

Cameron, T.A., 1988. A new paradigm for valuing non-market goods using referendum data. Journal of Environmental Economics and Management. 15: 355-379.

Chan, C., Zambahari, R., Kaul, U., Cohen, S.A. and Buchbinder, M., 2005. Outcomes in diabetic patients with multivessel disease and long lesions: results from the DECODE study. American Journal of Cardiology, 96 (Suppl. 7A), 31H.

Chan, J.L. and Andrade, E.B., 2011. Fear, social projection, and financial decision making. Journal of Marketing Research, 42, 121-129.

Corbacho, B. and Pinto-Prades, J.L.,. 2012. Health economic decision-making: A comparison between UK and Spain. British Medical Bulletin, 103 (1), 5-20. 
Diamond, P. and Vartiainen, H., 2007. Introduction to behavioral economics and its applications. In: Diamond, P. and Vartiainen, H., eds. 2007. Behavioral Economics and Its Applications. Princeton University Press.

Dolan, P. and Kahneman, D., 2008. Interpretations of utility and their implications for the valuation of health. The Economic Journal, 118, 215-234.

Elit, L.M., Leaven, M.N., Gafni, A., Whelan, T.J., Doig, G., Streiner, D.L. and Rosen, B., 1996. Patient preferences for therapy in advanced epithelial ovarian cancer: development, testing and application of a bedside decision instrument. Gynecologic Oncology, 62, 329-335.

Gervès, C., Bellanger, M.M. and Ankri,J., 2013. Economic analysis of the intangible impacts of informal care for people with Alzheimer's disease and other mental disorders. Value in Health, 16 (5), 745-754.

Greenberg, D., Bakhai, A., Neumann, P.J. and Cohen, D.J., 2004. Willingness to pay for avoiding coronary restenosis and repeat revascularization: results from a contingent valuation study. Health Policy, 70, 207-216.

Hausman, J., 2012. Contingent valuation: from dubious to hopeless. The Journal of Economic Perspectives, 43-56.

Hermalin, B. and Isen, A., 2008. A model of the effect of affect on economic decision making. Quantitative Marketing and Economics, 6 (1), 17-40.

Hsee, C. K. and Rottenstreich, Y., 2004. Music, pandas and muggers: On the affective psychology of value. Journal of Experimental Psychology: General, 133, 23-30

Jonas, D.E., Russell, L.B., Chou, J. and Pignone, M., 2010. Willingness-to-pay to avoid the time spent and discomfort associated with screening colonoscopy. Health Economics, 19 (10), 1193-1211.

Kelbaek, H., Helqvist, S., Thuesen, L., Kløvgaard, L., Jørgensen, E., Saunamäki, K., Krusell, L.R., Bøtker, H.E., Engstrøm, T., Jensen, G.V. and SCANDSTENT investigators., 2006. Sirolimus versus bare metal stent implantation in patients with total coronary occlusions: subgroup analysis of the Stenting Coronary Arteries in NonStress/Benestent Disease (SCANDSTENT) trial. American Heart Journal, 152(5), 8826.

King, G. and Zeng, L., 2001. Logistic regression in rare events data. Political analysis, 9 (2), 137-163.

König, M., Pfarr, C. and Zweifel, P., 2013. Mutual altruism: evidence from Alzheimer patients and their spouse caregivers. Working Paper 02-13. University of Bayreuth, Department of Law and Economics, Economic Discussion Papers.

König, M., and Wettstein, A., 2002. Caring for relatives with dementia: willingness-topay for a reduction in caregiver's burden. Expert Review of Pharmacoeconomics and Outcomes Research, 2 (6), 535-547. 
Kuppermann, M., Nease, R.F., Ackerson, L.M., Black, S.B., Shinefield, H.R. and Lieu, T.A., 2000. Parents' preferences for outcomes associated with childhood vaccinations. The Pediatric Infectious Disease Journal, 19 (2), 129-33.

Lee, S.J., Neumann, P.J., Churchill, W.H., Cannon, M.E., Weinstein, M.C. and Johannesson, M., 1997. Patients' willingness to pay for autologous blood donation. Health Policy, 40 (1).

León, C.J., Araña, J.E., Hanemann, M. W. and Riera, P., 2014. Heterogeneity and emotions in the valuation of non-use damages caused by oil spills. Ecological Economics, 97(January): 129-39.

Lerner, J.S., Small, D.A. and Loewenstein, G., 2004. Heart strings and purse strings: effects of emotions on economic transactions. Psychological Science, 15, 337-341.

Liu, J.T., Hammitt, J.D., Wang, V. and Liu J.L., 2000. Mother's willingness to pay for her own and her child's health: a contingent valuation study in Taiwan. Health Economics, 9 (4), 319-26.

Mathes, T., Jacobs, E., Morfeld, J-C. and Pieper, D., 2013. Methods of international health technology assessment agencies for economic evaluations - a comparative analysis. BMC Health Services Research, 13: 371.

Matthews, D., Rocchi, A. and Gafni, A., 2001. Factors affecting patients' and potential patients' preferences for periodontal anaesthesia. Journal of Dentistry, 29 (3), 173-9.

McFadden, D., 1974. Conditional logit analysis of qualitative choice behavior. In: Frontiers in econometrics. Edited by Paul Zarembka. Academic Press, New York.

Meyerhoff, A.S., Weniger, B.G. and Jacobs, R.J., 2001. Economic value to parents of reducing the pain and emotional distress of childhood vaccine injections. The Pediatric Infectious Disease Journal, 20 (11 Suppl), 57-62.

Moses, J.W., Leon, M.B., Popma, J.J., Fitzgerald, P.J., Holmes, D.R., O'Shaughnessy, C., Caputo, R.P., Kereiakes, D.J., Williams, D.O., Teirstein, P.S., Jaeger, J.L., Kuntz, R.E. and SIRIUS Investigators., 2003. Sirolimus-eluting stents versus standard stents in patients with stenosis in a native coronary artery. New England Journal of Medicine, $349,1315-23$.

Rick, S. and Loewenstein, G., 2008. The Role of Emotion in Economic Behavior. In Handbook of Emotions, Third Edition, edited by Michael Lewis, Jeannette M. HavilandJones, and Lisa Feldman Barrett. Guilford Press.

Robbins, J.M., Tilford, J.M., Gillaspy, S.R., Shaw, J.L., Simpson, D.D., Jacobs, R.F. and Wheeler J.G., 2002. Parental emotional and time costs predict compliance with respiratory syncytial virus prophylaxis. Ambulatory Pediatrics, 2, 444-448.

Sadri H., MacKeigan, L.D., Leiter L.A. and Einarson, T.R., 2005. Willingness to pay for inhaled insulin: a contingent valuation approach. Pharmacoeconomics, 23 (12), 12151227. 
Sebban, C., Browman, G., Gafni, A., Norman, G., Levine, M., Assouline, D. and Fiere, D., 1995. Design and validation of a bedside decision instrument to elicit a patient's preferences concerning allegoric bone marrow transplantation in chronic myeloid leukemia. American Journal of Hematology, 48, 221-227.

Shiv, B. and Fedorikhin, A., 1999. Heart and mind in conflict: the interplay of affect and cognition in consumer decision making. Journal of Consumer Research, 26 (December), 278-92.

Shiv, B., Loewenstein, G., Bechara, A., Damasio, H. and Damasio, A., 2005. Investment behavior and the negative side of emotion. Psychological Science, 16 (6), 435-39.

Slovic, P., 2007. If I look at the mass I will never act: psychic numbing and genocide. Judgment and Decision Making, 2(2), 79-95.

Suttorp, M.J., Laarman, G.J., Rahel, B.M., Kelder, J.C., Bosschaert, M.A., Kiemeneij, F., Ten Berg, J.M., Bal, E.T., Rensing, BJ., Eefting, F.D. and Mast, E.G., 2006. Primary Stenting of Totally Occluded Native Coronary Arteries II (PRISON II). A randomized comparison of bare metal stent implantation with sirolimus-eluting stent implantation for the treatment of total coronary occlusions. Circulation, 114, 921-928.

Yasunaga, H., Ide, H., Imamura, T. and Ohe, K., 2007. Women's anxieties caused by false positives in mammography screening: a contingent valuation survey. Breast Cancer Research and Treatment, 101 (1), 59-64. 
Table 1. Offered bids for each sample (in euros)

\begin{tabular}{|c|c|c|}
\hline First_bid & \multicolumn{2}{|c|}{ Follow-up bid } \\
\hline \multirow[b]{2}{*}{100} & bid $_{u p}$ & 400 \\
\hline & bid_down & 30 \\
\hline \multirow{2}{*}{400} & bid $_{u p}$ & 900 \\
\hline & bid_down & 100 \\
\hline \multirow{2}{*}{900} & bid $_{u p}$ & 1,500 \\
\hline & bid_down & 400 \\
\hline \multirow{2}{*}{1,500} & bid $_{u p}$ & 3,000 \\
\hline & bid_down & 900 \\
\hline \multirow{2}{*}{3,000} & bid $_{u p}$ & 6,000 \\
\hline & bid_down & 1,500 \\
\hline \multirow{2}{*}{6,000} & bid $_{u p}$ & 12,000 \\
\hline & bid_down & 3,000 \\
\hline \multirow{2}{*}{18,000} & bid $_{u p}$ & 30,000 \\
\hline & bid_down & 12,000 \\
\hline
\end{tabular}


Table 2 Socioeconomic characteristics. Survey and Spanish populations

\begin{tabular}{|c|c|c|}
\hline Variables & $\begin{array}{c}\text { Sample population } \\
(\mathrm{n}=1,479)\end{array}$ & Spain (2009) \\
\hline \multicolumn{3}{|l|}{$\operatorname{Age}^{1}$} \\
\hline $20-34$ & 29.5 & 28.3 \\
\hline $35-49$ & 28.3 & 29.9 \\
\hline $50-64$ & 22.5 & 21.5 \\
\hline $65+$ & 19.6 & 20.3 \\
\hline \multicolumn{3}{|l|}{ Gender $^{2}$} \\
\hline (\% female) & 50.7 & 50.6 \\
\hline \multicolumn{3}{|l|}{ Level of studies ${ }^{3}$} \\
\hline Compulsory education & 37.9 & 23.1 \\
\hline 1st level Secondary & 34.5 & 27.5 \\
\hline 2nd level Secondary & 8.3 & 21.0 \\
\hline Higher Education & 19.2 & 28.5 \\
\hline \multicolumn{3}{|l|}{ Employment ${ }^{4}$} \\
\hline Employed & 59.9 & 60.1 \\
\hline Unemployed & 40.1 & 39.8 \\
\hline \multicolumn{3}{|l|}{ HH average $\operatorname{size}^{5}$} \\
\hline Number of individuals & 3.1 & 2.9 \\
\hline \multicolumn{3}{|l|}{ Net HH income ${ }^{6}$} \\
\hline Up to $1,200 €$ & 39.6 & 45 \\
\hline From 1,201 to 3,000€ & 55.3 & 51.2 \\
\hline More than 3,000€ & 5.1 & 3.8 \\
\hline 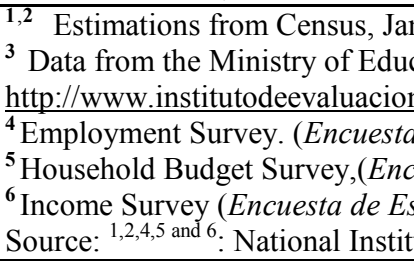 & $\begin{array}{l}\text { 2009. (Padrón Munic } \\
\text { n (Sistema Estatal de It } \\
\text { c.es/contenidos/pdfs/c4 } \\
\text { Doblación Activa) First } \\
\text { a de Presupuestos Fam } \\
\text { tura Salarial), 2006. } \\
\text { f Statistics. INE (http:) }\end{array}$ & ducación) \\
\hline
\end{tabular}


Table 3 Covariates distribution, by group

\begin{tabular}{|lcccc|}
\hline & $\begin{array}{c}\text { LE-A } \\
(\mathrm{n}=351)\end{array}$ & $\begin{array}{c}\text { LE-D } \\
(\mathrm{n}=399)\end{array}$ & $\begin{array}{c}\text { HE-A } \\
(\mathrm{n}=365)\end{array}$ & $\begin{array}{c}\text { HE-D } \\
(\mathrm{n}=364)\end{array}$ \\
\hline Age (average) & 45.4 & 46.5 & 48.3 & 47.7 \\
\hline Gender (\% female) & 44.4 & 41.1 & 58.9 & 58.5 \\
\hline Years of study (average) & 9.7 & 9.7 & 9.2 & 9.6 \\
\hline Laboral Status (\% employed) & 58.1 & 61.7 & 59.2 & 61.8 \\
\hline
\end{tabular}


Table 4. Parameters estimates. Ascending Sequence

\begin{tabular}{|c|c|c|c|c|c|c|c|c|}
\hline \multirow[t]{2}{*}{ Covariates } & \multicolumn{2}{|c|}{ Model 1} & \multicolumn{2}{|c|}{ Model 2} & \multicolumn{2}{|c|}{ Model 3} & \multicolumn{2}{|c|}{ Model 4} \\
\hline & Parameter & p-value & Parameter & p-value & Parameter & $\mathrm{p}$-value & Parameter & $\mathrm{p}$-value \\
\hline Constant & .1079 & .8030 & -.3312 & .4484 & .1712 & .6930 & -.2678 & .5410 \\
\hline Bid & -.1985 & .0000 & -.1994 & .0000 & -.1983 & .0000 & -.1995 & .0000 \\
\hline Age & .0040 & .4593 & .0016 & .7595 & .0040 & .4564 & .0016 & .7657 \\
\hline Gender & -.1749 & .3058 & -.0716 & .6738 & -.1741 & .3087 & -.0707 & .6784 \\
\hline $\begin{array}{c}\text { Laboral } \\
\text { status }\end{array}$ & .4526 & .0205 & .3780 & .0555 & .4562 & .0197 & .3802 & .0547 \\
\hline Education & .0500 & .0304 & .0540 & .0199 & .0500 & .0308 & .0539 & .0205 \\
\hline HRR & .0561 & .0000 & .0708 & .0000 & - & - & - & - \\
\hline $\mathrm{HE}$ & & & .9957 & .0000 & - & - & - & - \\
\hline HRRxHE & & & -.0288 & .0000 & - & - & - & - \\
\hline $\mathrm{HRR}_{7}$ & & & & & .3539 & .0000 & & \\
\hline $\mathrm{HRR}_{12}$ & & & & & .6970 & .0000 & & \\
\hline $\mathrm{HRR}_{17}$ & & & & & .8182 & .0000 & & \\
\hline $\mathrm{LE}_{7}$ & & & & & & & .5206 & .0000 \\
\hline $\mathrm{LE}_{12}$ & & & & & & & .8579 & .0000 \\
\hline $\mathrm{LE}_{17}$ & & & & & & & 1.0685 & .0000 \\
\hline $\mathrm{HE}_{2}$ & & & & & & & 1.0011 & .0000 \\
\hline $\mathrm{HE}_{7}$ & & & & & & & 1.2028 & .0000 \\
\hline $\mathrm{HE}_{12}$ & & & & & & & 1.5544 & .0000 \\
\hline $\mathrm{HE}_{17}$ & & & & & & & 1.5819 & .0000 \\
\hline$\rho$ & .8043 & .0000 & .7996 & .0000 & .8046 & .0000 & .8001 & .0000 \\
\hline $\mathrm{LnL}$ & \multicolumn{2}{|c|}{$-2,558.450$} & \multicolumn{2}{|c|}{$-2,543.546$} & \multicolumn{2}{|c|}{$-2,555.111$} & \multicolumn{2}{|c|}{$-2,539.017$} \\
\hline \multicolumn{9}{|c|}{ WTP estimates } \\
\hline & \multicolumn{2}{|c|}{ Model 1} & \multicolumn{2}{|c|}{ Model 2} & \multicolumn{2}{|c|}{ Model 3} & \multicolumn{2}{|c|}{ Model 4} \\
\hline & & & $\mathrm{HE}$ & LE & & & $\mathrm{HE}$ & LE \\
\hline 2 & \multicolumn{2}{|c|}{$5,417.64$} & $7,698.85$ & $2,997.11$ & \multicolumn{2}{|c|}{$5,192.58$} & $7,615.86$ & $2,597.67$ \\
\hline 7 & \multicolumn{2}{|c|}{$6,832.18$} & $8,751.30$ & $4,773.14$ & \multicolumn{2}{|c|}{$6,976.52$} & $8,626.41$ & $\overline{5,207.44}$ \\
\hline 12 & \multicolumn{2}{|c|}{$8,246.72$} & $9,803.75$ & $6,549.17$ & \multicolumn{2}{|c|}{$8,706.14$} & $10,388.71$ & $6,897.82$ \\
\hline 17 & \multicolumn{2}{|c|}{$9,661.26$} & $10,856.21$ & $8,325.20$ & \multicolumn{2}{|c|}{$9,317.24$} & $10,526.95$ & $7,953.33$ \\
\hline
\end{tabular}


Table 5. Parameters estimates. Descending Sequence

\begin{tabular}{|c|c|c|c|c|c|c|c|c|}
\hline \multirow[t]{2}{*}{ Covariates } & \multicolumn{2}{|c|}{ Model 1} & \multicolumn{2}{|c|}{ Model 2} & \multicolumn{2}{|c|}{ Model 3} & \multicolumn{2}{|c|}{ Model 4} \\
\hline & Parameter & p-value & Parameter & $\mathrm{p}$-value & Parameter & p-value & Parameter & p-value \\
\hline Constant & .3781 & .5204 & -.8332 & .1507 & 1.3282 & .0236 & .3700 & .5166 \\
\hline Bid & -.2472 & .0000 & -.2484 & .0000 & -.2473 & .0000 & -.2484 & .0000 \\
\hline Age & .0035 & .6379 & .0097 & .1910 & .0033 & .6556 & .0097 & .1909 \\
\hline Gender & -.0543 & .8028 & .2860 & .2037 & -.0564 & .7956 & .2866 & .2033 \\
\hline $\begin{array}{c}\text { Laboral } \\
\text { status }\end{array}$ & .5290 & .0371 & .6337 & .0112 & .5272 & .0378 & .6317 & .0115 \\
\hline Education & .0996 & .0005 & .1018 & .0004 & .0992 & .0005 & .1019 & .0004 \\
\hline HRR & .0279 & .0000 & .0364 & .0000 & & & & \\
\hline $\mathrm{HE}$ & & & 1.5451 & .0000 & & & & \\
\hline HRRxHE & & & -.0193 & .0196 & & & & \\
\hline $\mathrm{HRR}_{27}$ & & & & & -.2175 & .0064 & & \\
\hline $\mathrm{HRR}_{22}$ & & & & & -.3673 & .0000 & & \\
\hline $\mathrm{HRR}_{17}$ & & & & & -.4180 & .0000 & & \\
\hline $\mathrm{LE}_{27}$ & & & & & & & -.2530 & .0142 \\
\hline $\mathrm{LE}_{22}$ & & & & & & & -.4548 & .0000 \\
\hline $\mathrm{LE}_{17}$ & & & & & & & -.5434 & .0000 \\
\hline $\mathrm{HE}_{32}$ & & & & & & & .9301 & .0001 \\
\hline $\mathrm{HE}_{27}$ & & & & & & & .7585 & .0018 \\
\hline $\mathrm{HE}_{22}$ & & & & & & & .6733 & .0057 \\
\hline $\mathrm{HE}_{17}$ & & & & & & & .6718 & .0050 \\
\hline$\rho$ & .8967 & .0000 & .8904 & .0000 & .8969 & .0000 & .8905 & .0000 \\
\hline $\mathrm{LnL}$ & \multicolumn{2}{|c|}{$-2,355.989$} & \multicolumn{2}{|c|}{$-2,345.139$} & \multicolumn{2}{|c|}{-2354.755} & \multicolumn{2}{|c|}{-2343.895} \\
\hline \multicolumn{9}{|c|}{ WTP estimates } \\
\hline & \multicolumn{2}{|c|}{ Model 1} & \multicolumn{2}{|c|}{ Model 2} & \multicolumn{2}{|c|}{ Model 3} & \multicolumn{2}{|c|}{ Model 4} \\
\hline & & & $\mathrm{HE}$ & LE & & & $\mathrm{HE}$ & LE \\
\hline 32 & \multicolumn{2}{|c|}{$10,861.05$} & $12,936.49$ & $9,213.35$ & \multicolumn{2}{|c|}{$11,028.82$} & $13,108.86$ & $9,365.39$ \\
\hline 27 & \multicolumn{2}{|c|}{$10,296.56$} & $12,592.59$ & $8,479.33$ & \multicolumn{2}{|c|}{$10,149.20$} & $12,418.35$ & $8,347.08$ \\
\hline 22 & \multicolumn{2}{|c|}{$9,732.07$} & $12,248.69$ & $7,745.30$ & \multicolumn{2}{|c|}{$9,543.68$} & $12,075.45$ & $7,534.81$ \\
\hline 17 & \multicolumn{2}{|c|}{$9,167.57$} & $11,904.78$ & $7,011.27$ & \multicolumn{2}{|c|}{$9,338.45$} & $12,069.22$ & $7,178.24$ \\
\hline
\end{tabular}

